\title{
Unfolded protein response-induced dysregulation of calcium homeostasis promotes retinal degeneration in rat models of autosomal dominant retinitis pigmentosa
}

\author{
V Shinde ${ }^{1}$, P Kotla $^{1}$, C Strang ${ }^{1}$ and M Gorbatyuk ${ }^{\star, 1}$
}

The molecular mechanism of autosomal dominant retinitis pigmentosa (ADRP) in rats is closely associated with a persistently activated unfolded protein response (UPR). If unchecked, the UPR might trigger apoptosis, leading to photoreceptor death. One of the UPR-activated cellular signaling culminating in apoptotic photoreceptor cell death is linked to an increase in intracellular $\mathrm{Ca}^{2+}$. Therefore, we validated whether ADRP retinas experience a cytosolic $\mathrm{Ca}^{2+}$ overload, and whether sustained UPR in the wild-type retina could promote retinal degeneration through $\mathrm{Ca}^{2+}$-mediated calpain activation. We performed an ex vivo experiment to measure intracellular $\mathrm{Ca}^{2+}$ in ADRP retinas as well as to detect the expression levels of proteins that act as $\mathrm{Ca}^{2+}$ sensors. In separate experiments with the subretinal injection of tunicamycin (UPR inducer) and a mixture of calcium ionophore (A231278) and thapsigargin (SERCA2b inhibitor) we assessed the consequences of a sustained UPR activation and increased intracellular $\mathrm{Ca}^{2+}$ in the wild-type retina, respectively, by performing scotopic ERG, histological, and western blot analyses. Results of the study revealed that induced UPR in the retina activates calpain-mediated signaling, and increased intracellular $\mathrm{Ca}^{2+}$ is capable of promoting retinal degeneration. A significant decline in ERG amplitudes at 6 weeks post treatment was associated with photoreceptor cell loss that occurred through calpain-activated CDK5-pJNK-Csp3/7 pathway. Similar calpain activation was found in ADRP rat retinas. A twofold increase in intracellular $\mathrm{Ca}^{2+}$ and up- and downregulations of ER membrane-associated $\mathrm{Ca}^{2+}$-regulated IP3R channels and SERCA2b transporters were detected. Therefore, sustained UPR activation in the ADRP rat retinas could promote retinal degeneration through increased intracellular $\mathrm{Ca}^{2+}$ and calpain-mediated apoptosis.

Cell Death and Disease (2016) 7, e2085; doi:10.1038/cddis.2015.325; published online 4 February 2016

Rat models of autosomal dominant retinitis pigmentosa (ADRP), the S334ter and $\mathrm{P} 23 \mathrm{H}$ Rho rats expressing truncated and mutant mouse rhodopsins, experience severe retinal degeneration. The ADRP progression in these animals is characterized by an activated unfolded protein response (UPR) and the mitochondrial dysfunction. ${ }^{1-3}$ Recent work conducted with ADRP mice has revealed that the persistently activated UPR could be responsible for promoting retinal degeneration via the activation of an inflammatory response. ${ }^{4}$ However, in addition to modulated expression of interleukins IL- $1 \mathrm{~b}$ and IL- 6 , the activated UPR may promote cytotoxicity through $\mathrm{Ca}^{2+}$-depleted $\mathrm{ER}$, thus affecting the function of the mitochondria. ${ }^{5}$

It is known that the ER serves as the primary store in cells for $\mathrm{Ca}^{2+}$, a second messenger, participating in a wide variety of physiological functions, including signal transduction, muscle contraction, protein, and hormone secretion. The normal ER functions to regulate and control intracellular $\mathrm{Ca}^{2+}$, thus governing protein synthesis, gene expression, secretion, metabolism, and apoptosis. ${ }^{6}$ Therefore, the ER disturbance results in a release of $\mathrm{Ca}^{2+}$ into the cytosol, after which free $\mathrm{Ca}^{2+}$ can be either transported to the mitochondria or directly activate cytotoxic cellular pathways. ${ }^{7}$ The findings support the fact that $\mathrm{Ca}^{2+}$ transport from the ER to mitochondria has a significant role in regulating cellular bioenergetics, the production of reactive oxygen species, the induction of autophagy, and apoptosis. ${ }^{8-10}$

It has been found that in photoreceptors, different cellular compartments demonstrate a marked variation in $\mathrm{Ca}^{2+}$ concentrations, perhaps associated with their varying functions, including the transduction of photon energy into an electrical signal and transcriptional, translational, metabolic, and synaptic properties. ${ }^{11}$ For example, the CNGCs channels regulated by the phototransduction cascade and the VGCCs channels regulated by light-induced cell membrane hyperpolarization are located in the outer segments (OS) and in the cell body and synaptic terminal, respectively. This differential localization results in high $\mathrm{Ca}^{2+}$ influx in the OS and low $\mathrm{Ca}^{2+}$ influx in the cell body and synaptic terminal in dark conditions. In addition, SOCE channels in the plasma membrane, SERCA

\footnotetext{
${ }^{1}$ Department of Vision Sciences, University of Alabama at Birmingham, Birmingham, AL, USA

*Corresponding author: M Gorbatyuk, Department of Vision Sciences, University of Alabama at Birmingham, 1670 University Blvd., Birmingham 35233, AL, USA. Tel: +1 205 9346762; Fax: +1 205 9343425; E-mail: mgortk@uab.edu

Abbreviations: UPR, unfolded protein response; ADRP, autosomal dominant retinitis pigmentosa; RP, retinitis pigmentosa; Rho, rhodopsin; RPE, retinal pigment epithelium; ER, endoplasmic reticulum; ERG, electroretinography; OCT, optical coherence tomography; OS, outer segment; IS, inner segment; ONL, outer nuclear layer; WT, wild type; SD, Sprague-Dawley; H\&E, hematoxylin and eosin; Tn, tunicamycin; Tg, thapsigargin; pIP3R, inositol 1, 4, 5-triphosphate receptor; BI-1, Bax inhibitor-1; VGCC, voltage-gated calcium channel; SOCE, store-operated calcium entry; AIF, apoptosis-inducing factor-1; CNGC, cyclic nucleotide-gated calcium channel; VDAC, voltage-dependent anion channel; CAST, calpastatin; CN, calcineurin; ROS, reactive oxygen species; CRN, calreticulin; MTT, 3-(4,5-dimethylthiazol-2-yl)-2,5-diphenyl tetrazolium; CDK5, cyclin-dependent-like kinase 5; JNK, cJUN N-terminal kinase; mTOR, mechanistic target of rapamycin; AKT, protein kinase B

Received 12.6.15; revised 15.9.15; accepted 30.9.15; Edited by A Verkhratsky
} 
transporters, IP3 receptors, and ryanodine receptors in the $E R$, and the VDAC channels in the mitochondria located in the inner segment (IS) have also been shown to contribute to the regulation of intracellular $\mathrm{Ca}^{2+}$ in photoreceptors. ${ }^{12,13}$

Despite the fact that historically cell death associated with calcium ion perturbations has been primarily recognized as necrosis, recent evidence suggest that more complex cell death scenarios could be associated with changes in the concentrations of $\mathrm{Ca}^{2+}$. 7 Thus, $\mathrm{Ca}^{2+}$-induced cell death in addition to apoptotic cell death has been proposed to occur in the outer nuclear layer (ONL) of the retina of transgenic animals mimicking human retinal degeneration, resulting in the massive activation of PKG, calpain, HDAC, and PARP activation. ${ }^{14}$

There are several studies supporting the hypothesis that $\mathrm{Ca}^{2+}$-induced photoreceptor cell death has a crucial role in ADRP pathogenesis. ${ }^{15-18}$ Despite the fact that progress has been made in understanding the significance of $\mathrm{Ca}^{2+}$ overload, direct evidence of $\mathrm{Ca}^{2+}$ overload in ADRP photoreceptors has not been provided. Importantly, the role of an activated UPR in promoting $\mathrm{Ca}^{2+}$-mediated cytotoxicity in degenerating photoreceptors and the link between UPRmodulated IP3, ryanodine, and SERCA channel activities and retinal degeneration has not yet been established.

Therefore, we hypothesized that a persistently activated UPR contributes into an intracellular $\mathrm{Ca}^{2+}$ overload in ADRP retinas and a cytosolic $\mathrm{Ca}^{2+}$ overload triggers a loss of photoreceptor function, eventually leading to photoreceptor cell death in rat models of ADRP.

\section{Results}

Transgenic S334ter and $\mathrm{P} 23 \mathrm{H}$ Rho rats experience a cytosolic $\mathrm{Ca}^{2+}$ increase in their photoreceptors. Previous studies from our laboratory have shown that the S334ter and $\mathrm{P} 23 \mathrm{H}$ Rho rats have retinal degeneration associated with persistently activated UPR and disrupted mitochondrial membrane potential (MMP), resulting in calpain activation and the release of cytochrome $\mathrm{C}$ and AIF from mitochondria. ${ }^{1,2}$ However, it has been demonstrated that activation of the calpain system requires intracellular $\mathrm{Ca}^{2+}$ concentrations of at least tens of $\mu \mathrm{M},{ }^{19}$ whereas the intracellular $\mathrm{Ca}^{2+}$ concentrations in dark-adapted photoreceptors range only from $300-500 \mathrm{nM}^{20}$ This made us question whether the perturbance of ER homeostasis could promote enough $\mathrm{Ca}^{2+}$ release to result in the uptake of $\mathrm{Ca}^{2+}$ by mitochondria. Other studies have demonstrated that inhibition of $\mathrm{Ca}^{2+}$ can be beneficial by delaying ERG amplitude attenuation. ${ }^{21,22}$ However, direct evidence of $\mathrm{Ca}^{2+}$ overload in photoreceptor cells has not yet been provided.

Before detection of the $\mathrm{Ca}^{2+}$ load in ADRP retinas with ongoing UPR, we validated the method of $\mathrm{Ca}^{2+}$ measurement and provided proof of principle that the activated UPR causes the release of the $\mathrm{Ca}^{2+}$ into the cytosol. To that end, we performed subretinal injections of P30 SD rats with tunicamycin (Tn), which has been previously demonstrated to activate the UPR in the retina. ${ }^{4} \mathrm{Tn}$ was injected into the right eye for detection of levels of intracellular $\mathrm{Ca}^{2+}$ in photoreceptors with an experimentally induced UPR response. Vehicle injection into the left eye served as a control. Figure 1 and Supplementary Table S2 present the results of the study evidencing that the activated UPR provokes $\mathrm{Ca}^{2+}$ overload in the cytosol of photoreceptors.

Next, we measured cytosolic $\mathrm{Ca}^{2+}$ in S334ter and $\mathrm{P} 23 \mathrm{H}$ Rho photoreceptors. Our data showed that photoreceptors had an overload of intracellular $\mathrm{Ca}^{2+}$ at P30 that was in agreement with the rate of retinal degeneration found in these animals http://www.ucsfeye.net/mlavailRDratmodels.shtml. Therefore, after registering a free cytosolic $\mathrm{Ca}^{2+}$ increase, we decided to dissect the sources of such overload by testing the expression of $\mathrm{Ca}^{2+}$ signaling proteins specific for different compartments of photoreceptor cells.

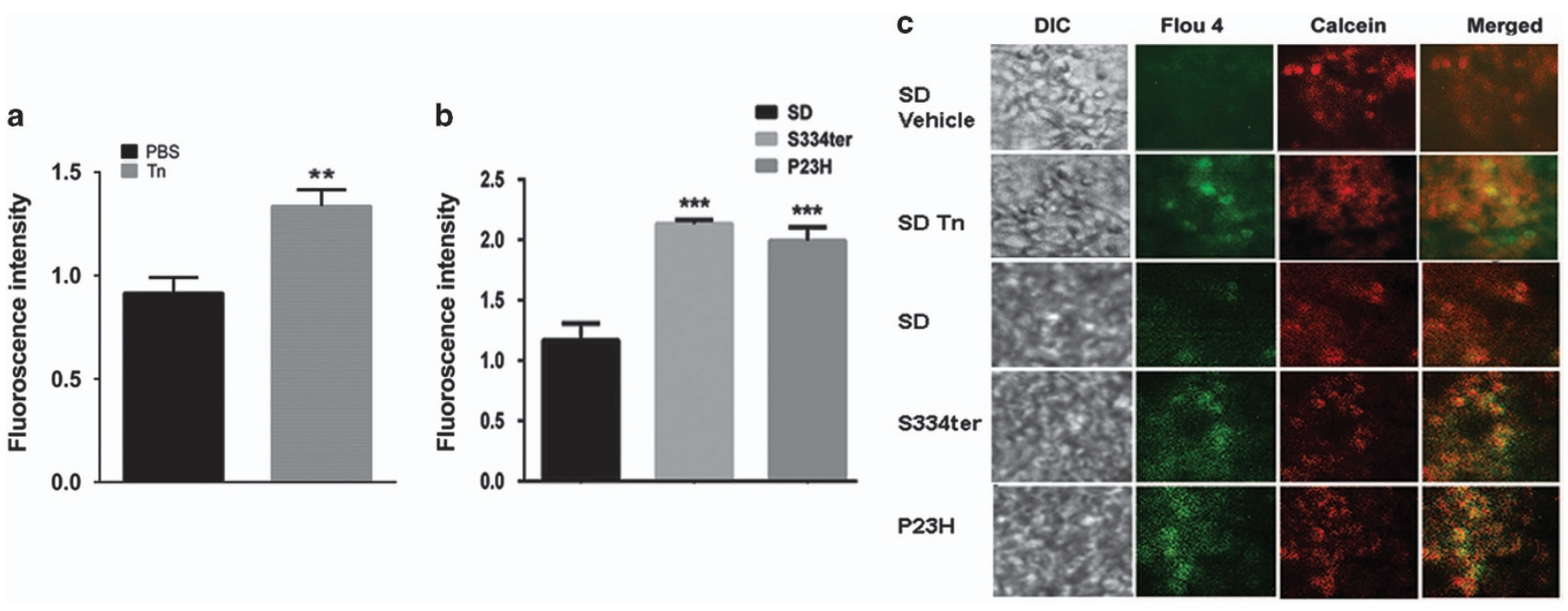

Figure 1 The $\mathrm{Ca}^{2+}$ cytosolic increase is detected in SD rat retinas injected with tunicamycin and in ADRP S334ter and P23H RHO rat retinas ( $\left.N=4\right)$. (a) A measurement of the fluorescent intensity in viable photoreceptors of SD retinas injected with Tn. Means of $45.78 \pm 3.801(N=5)$ and $66.79 \pm 3.967(N=5)$ were found by using the image $\mathrm{J}$ program and $t$-test. (b) A measurement of the fluorescent intensity in viable photoreceptors of S334ter and P23H RHO rats $(N=4)$. Means of $2.13 \pm 0.032$ and $1.99 \pm 0.113$ $(P<0.001$ for both) were found by one-way ANOVA in S334ter and P23H Rho retinas, respectively, compared with SD retinas (1.16 \pm 0.138$)$. Data are shown as means \pm S.E.M. (c) Images of SD photoreceptors treated with Tn and vehicle (two upper panels) and naive SD, S334ter, and P23H RHO photoreceptors up-taking the Flou 4 AM dye. The isolated retinas were incubated in a mixture of the Flou4AM detecting free cytosolic $\mathrm{Ca}^{2+}$ and the calcein AM detecting viable photoreceptor cells. ${ }^{* *},{ }^{* \star *} P<0.01$ 
Increased free cytosolic $\mathrm{Ca}^{2+}$ is linked to the overexpression of ER membrane $\mathrm{Ca}^{2+}$-channels and cytosolic $\mathrm{Ca}^{2+}$ signaling proteins. The diffuse accumulation of the cGMP and S334ter and $\mathrm{P} 23 \mathrm{H}$ Rho rats has been previously shown in the ONL of the retina, suggesting a $\mathrm{Ca}^{2+}$ increase in S334ter and $\mathrm{P} 23 \mathrm{H}$ RHO photoreceptors. ${ }^{14}$ Because VGCC expression is known to reflect the modulation in $\mathrm{Ca}^{2+}$ concentration, ${ }^{23}$ we tested the level of VGCC protein expression by western blot analysis and found no difference between control and experimental groups. These data suggested that the $\mathrm{Ca}^{2+}$ increase registered in transgenic photoreceptors is not generated by VGCC malfunctioning. Keeping that in mind, we then tested whether the source of the $\mathrm{Ca}^{2+}$ elevations was from intracellular compartments by measuring the expression levels of the cytosolic $\mathrm{Ca}^{2+}$-signaling proteins calpastatin and calcineurin, the ER resident calreticulin (CRN), and the mitochondrial VDAC protein.

The expression of cytosolic calpastatin (CAST), a $\mathrm{Ca}^{2+}$-dependent cysteine protease inhibitor of calpains, was upregulated in both transgenic retinas. Both mRNA and protein levels were increased at P21 (Figures $2 a$ and b, Supplementary Table S3 and S4). Interestingly, the CAST overexpression in this experiment tightly correlated with previously detected calpain activity in these animals at P21 and $\mathrm{P} 30,{ }^{1,2}$ confirming calpain-mediated signaling in these retinas. In addition, cytosolic calcineurin $(\mathrm{CN})$, a $\mathrm{Ca}^{2+}$ - and calmodulin-dependent serine-threonine phosphatase was also upregulated in both transgenic retinas at P30 (Figure 2c and Supplementary Table S3 and S4). Increases in calciumdependent calpastatin and calcineurin protein expression in ADRP retinas further serve as additional evidence of cytoplasmic $\mathrm{Ca}^{2+}$ overload.

Next, we analyzed the expression of the mitochondrial VDAC, a multifunctional protein know to participate in ERmitochondria cross-talk, the transport of ROS, ATP, $\mathrm{Ca}^{2+}$, metabolites, and apoptosis ${ }^{24}$ and found that Vdac mRNA was significantly higher in both transgenic retinas at P21 and P30 (Figure 2d and Supplementary Table S3). The elevation of VDAC expression in degenerating photoreceptors was then confirmed by immunohistochemical analysis of retinal cryostat sections treated with anti-VDAC antibody at P30 (Figure 2e).

The ER resident $\mathrm{Ca}^{2+}$-binding protein $\mathrm{CRN}$ is known to be sensitive to changes in the concentration of $\mathrm{Ca}^{2+}$. For example, it has been demonstrated that its promoter encompassing 115-260 and 685-1736 regions and containing the CCAAT nucleotide motif is believed to be activated in response to $\mathrm{Ca}^{2+}$ depletion by increasing mRNA levels. ${ }^{25}$ Therefore, knowing about a persistently activated UPR, we were not surprised to learn that the Crn mRNA was markedly (over twofold) elevated in both transgenic retinas at P21 and (over fourfold) in S334ter retinas at P40 (Figure $2 f$ and Supplementary Table S3). Interestingly, the CRN protein level was not elevated in these retinas. a

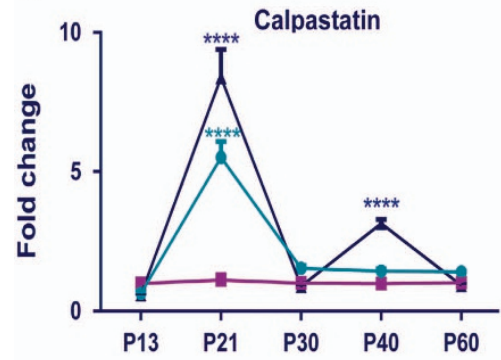

d

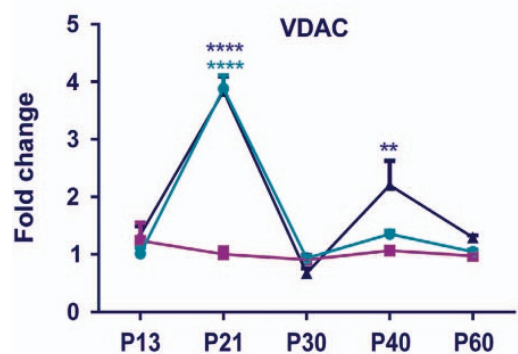

b
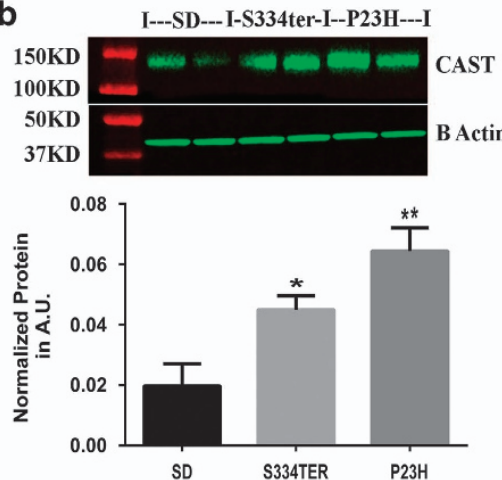

e

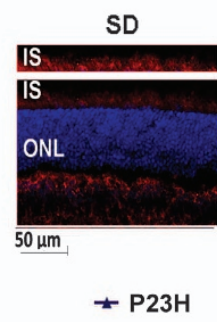

$\mathrm{P} 23 \mathrm{H}$

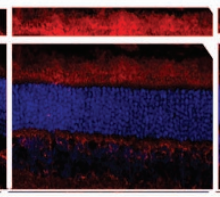

$\rightarrow$ S334ter

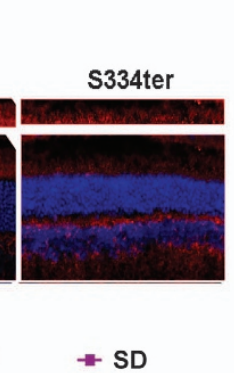

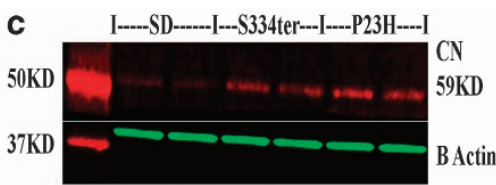

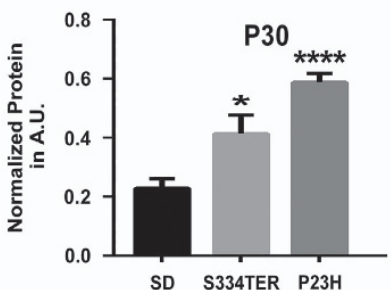

f

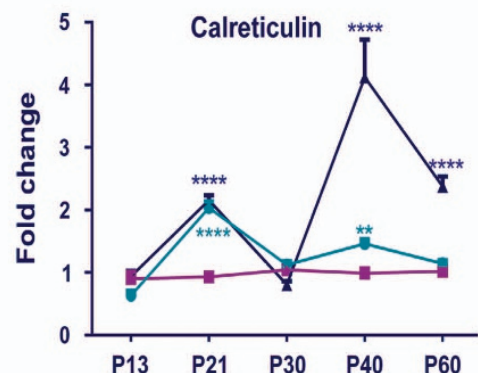

Figure 2 The expression of $\mathrm{Ca}^{2+}$ sensing genes and proteins in ADRP retinas measured by qRT-PCR $(N=4)$ and western blot $(N=4)$ analyses. (a) Analyzing data by twoway ANOVA, calpastatin mRNA expression was found to be upregulated in ADRP retinas at P21 as compared wth $\mathrm{SD}(P<0.0001)$. The same trend was observed at P40 $(P<0.0001)$. (b) Calpastatin protein expression was elevated in ADRP retinas at $\mathrm{P} 21$ versus SD retinas $(P<0.05$ and $P<0.01$, respectively). (c) At P30, both ADRP retinas demonstrated increases in calcineurin $(P<0.05$ and $P<0.0001$, respectively) compared wth controls. (d) The Vdac mRNA expression was found to be upregulated in both ADRP retinas at P21 $(P<0.0001$ for both strains). At P40, only P23H Rho retinas demonstrated changes in Vdac mRNA expression as compared with control $(P<0.01)$. (e) Immunohistochemical analysis of ADRP cryostat retinas stained against VDAC protein at P30 revealed an increase in the VDAC expression in the inner segments of photoreceptors. (f) Marked upregulation in calreticulin expression was found in P21-P60 ADRP retinas $(P<0.0001)$. Data are shown as means $\pm S$.E.M. Images of western blots treated with a correspondent antibody are shown above the graphs for the calculation of individual proteins. ${ }^{* * * * * * \star *} P<0.01$ 
To verify the ER's involvement in the elevation of free cytosolic $\mathrm{Ca}^{2+}$ (Figure 1), we analyzed the expression of ER resident $\mathrm{Ca}^{2+}$-sensing receptor proteins: phosphorylated $(p)$ IP3R receptor, SERCA2b, and Bax inhibitor-1 (BI-1) (Figure 3 and Supplementary Tables S3 and S4). We learned that Ip3r mRNA was elevated in both transgenic retinas. However, the highest mRNA level was found in $\mathrm{P} 23 \mathrm{H}$ Rho retinas
(Figure 3a). pIP3R protein was upregulated at both time points, suggesting changes in the IP3 channel activity on the ER membrane (Figure $3 b$ ). These changes tightly correlated with the observed elevation of $\mathrm{Bl}-1$ mRNA and protein (Figures $3 c$ and d). In general, BI-1 is known to be an IP3Rinteracting protein, enhancing IP3R activity and resulting in lower steady-state $\mathrm{Ca}^{2+}$ within the ER. ${ }^{26}$ Consequently, cells
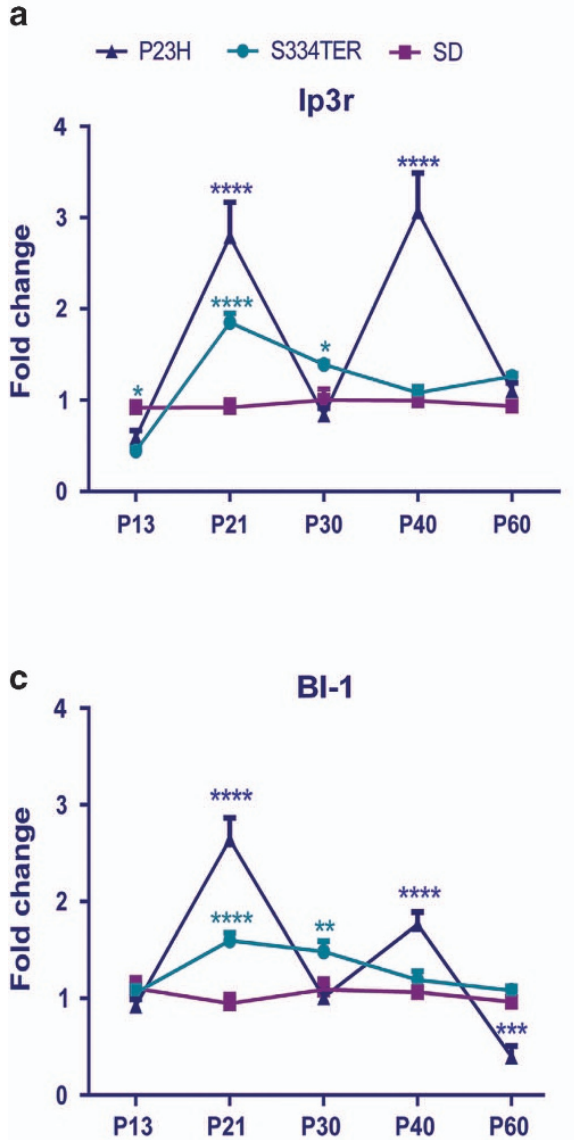

e

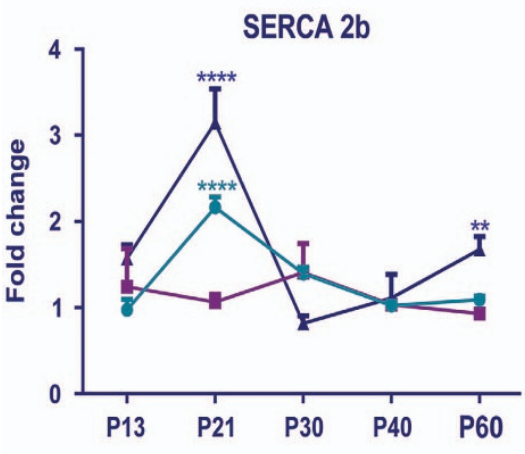

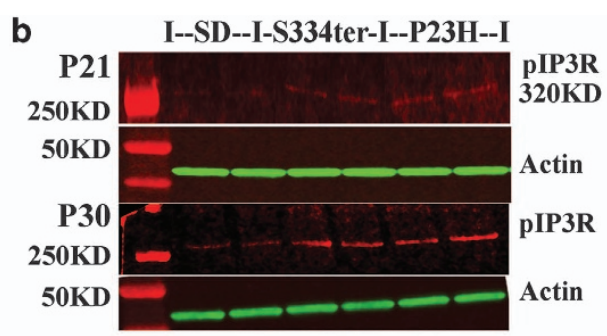
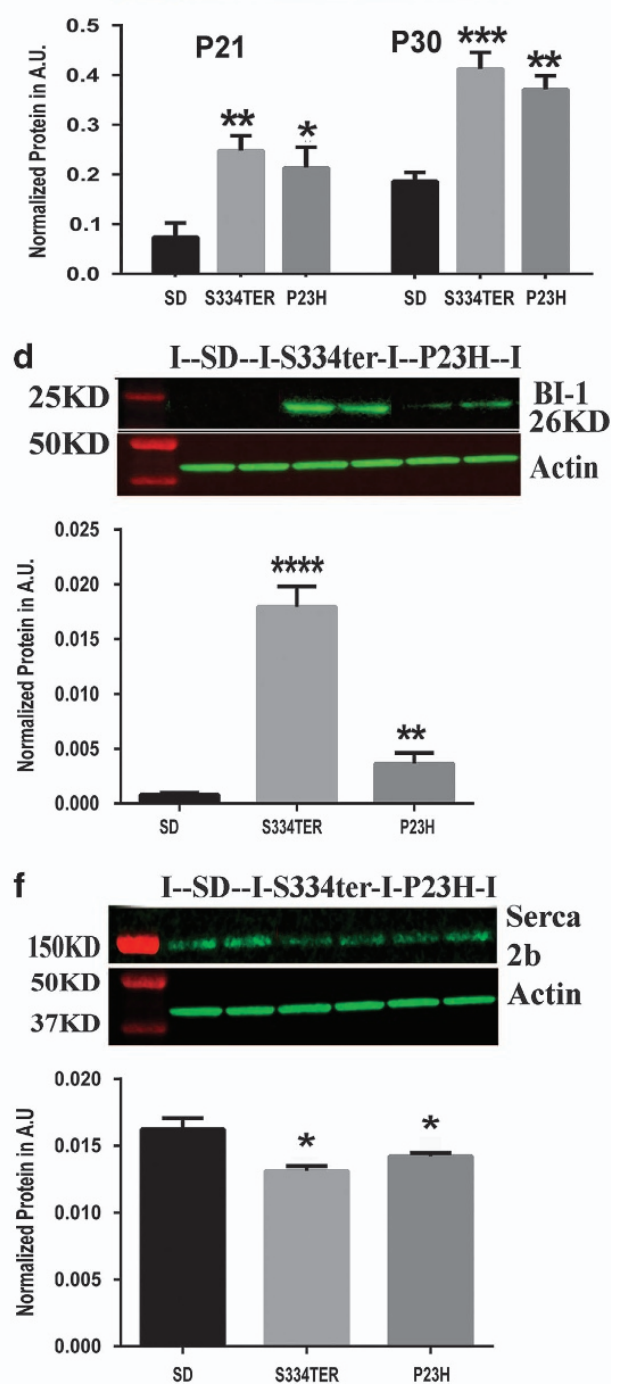

Figure 3 The expression of ER membrane $\mathrm{Ca}^{2+}$ channels in ADRP retinas detected by qRT-PCR and western blot analyses $(N=4)$. (a) Fold changes in Ipr3r mRNA expression in ADRP retinas were observed from P21 to P40 and analyzed by two-way ANOVA. (b1) The pIP3R protein expression in ADRP retinas at P21 and P30. (c) The Bi-1 mRNA expression in ADRP retinas from P13 to P60 is shown. (d) The expression of the BI-1 protein in P21 ADRP retinas. The SS34ter retinas demonstrated a marked 56.66-fold overproduction of the $\mathrm{Bl}-1$ protein compared with $\mathrm{P} 23 \mathrm{H}$ Rho retinas, which had a 10-fold increase in Bl-1 protein compared with SD $(P<0.0001$ and $P<0.01$, respectively). (e and f) Interestingly, the SERCA2b gene and protein expression reflected an opposite pattern of changes. Although at P21, the Serca2b mRNAs were upregulated $(P<0.0001$ for both strains) (e), the SERCA2b protein level was lower in both ADRP rat retinas. (f) Data are shown as means \pm S.E.M. Images of western blots treated with a correspondent antibody are shown above the graphs for the calculation of individual proteins. ${ }^{*, * *, * \star *, * * \star *} P<0.01$ 
overexpressing $\mathrm{Bl}-1$ are known to have a reduced luminal concentration of $\mathrm{Ca}^{2+}$ in the $\mathrm{ER}^{27}$ In the retina, the link between $\mathrm{BI}-1$ and the IP3 has not been demonstrated so far. Therefore, we performed a binding assay, immunoprecipitating IP3R in rat retinal protein extracts and running western blot analysis for BI-1 (Supplementary Figure S1). Our data indicated that $\mathrm{BI}-1$ is a binding partner of IP3R that could upregulate IP3R expression in the retina.

Another ER transmembrane protein, SERCA2b, transfers $\mathrm{Ca}^{2+}$ from the cytosol of the cell to the lumen of the ER. Interestingly Serca2b mRNA was elevated in both transgenic retinas at P21 (Figure $3 e$ ), whereas the SERCA2b protein was observed to diminish (Figure $3 e$ ). Therefore, the abovementioned upregulation of pIP3R and $\mathrm{BI}-1$ and the reduction of the SERCA2b in the ADRP rat models suggests $\mathrm{Ca}^{2+}$ dysregulation in the ER and the $\mathrm{Ca}^{2+}$ efflux to the cytosol in photoreceptors (Figure 1).

We next wanted to verify whether induction of the UPR in WT retinas and cultured WT photoreceptors resulted in altered expressions of $\mathrm{ER} \mathrm{Ca}^{2+}$ channel proteins and the cytosolic $\mathrm{Ca}^{2+}$-sensing proteins similar to that shown for ADRP retinas.

UPR activation in WT retinas and photoreceptors induces $\mathrm{Ca}^{2+}$-sensing protein expression, resulting in photoreceptor cell death. We isolated photoreceptors from SD retinas and cultured them to study the impact of the treatment with Tn on photoreceptor cell death (Figure 4). First, we confirmed that the cultured retinal cells were not contaminated by other retinal cell types by detecting specific cell markers such as RPE65 (RPE), GNAT2 (cones), Green opsin (cones), Thy-1 (ganglion cells), and rhodopsin by semiquantitative PCR (Figure 4a). Then we tested different concentrations of $\mathrm{Tn}$, to identify the concentration necessary to induce the UPR in cultured rat photoreceptors and affect cell viability. Previously, we have used Tn and demonstrated that a persistently activated UPR is capable of inducing retinal degeneration. ${ }^{4}$ Using the MTT assay, we measured the intensity of viable photoreceptor cells to identify a correlation between Tn dose and the number of surviving photoreceptors after $48 \mathrm{~h}$ (Figure 4b). Because we found that all the used concentrations of Tn were detrimental for photoreceptors we chose to use the lowest dose, $2 \mu \mathrm{g} / \mathrm{ml}$ of $\mathrm{Tn}$ to treat photoreceptors. Under these conditions, we confirmed that photoreceptor cell death occurred within $18 \mathrm{~h}$ through the upregulation of calpain activity. These results indicated that the ER homeostasis in cultured photoreceptors was compromised, leading to calpain-associated photoreceptor cell death (Figure 4c and Supplementary Table S5).

Subretinal injection with $0.02 \mu \mathrm{g} / \mathrm{eye}$ of Tn in WT retinas also resulted in calpain overexpression measured 4 days after the injection. In addition to calpain, we observed an increase in the pIP3R and the $\mathrm{Bl}-1$ proteins (Figures $4 \mathrm{~d}-\mathrm{f}$ and Supplementary Table S6). More surprising, SERCA2b protein was significantly upregulated (over 8.25 -fold) in Tn-treated retinas compared wth ADRP retinas, suggesting that at this stage of the UPR, the retinal cells are attempting to recover the balance between $\mathrm{Ca}^{2+}$ efflux and influx. In addition, consistent with $\mathrm{ADRP}$ retinas, we also observed the upregulation of $\mathrm{CN}$ by 1.5-fold in Tn-treated retinas. Together, these results mimic the situation with a persistently activated UPR in ADRP retinas and provide proof of principle that ER stress modulates expression of ER membrane $\mathrm{Ca}^{2+}$-regulated proteins, resulting in $\mathrm{Ca}^{2+}$-induced calpain activation and $\mathrm{Ca}^{2+}$-facilitated photoreceptor cell death. Therefore, we were then curious as to whether free cytosolic ER $\mathrm{Ca}^{2+}$ depletion and elevated cytoplasmic $\mathrm{Ca}^{2+}$ could promote retinal degeneration similar to that observed in ADRP retinas.

Increased cytosolic $\mathrm{Ca}^{2+}$ promotes the loss of photoreceptor function in the WT retinas. Knowing that the compromised ER integrity persistently promotes $\mathrm{Ca}^{2+}$ leakage into the cytosol, the next challenge was to design an experiment that stimulated efflux of $\mathrm{Ca}^{2+}$ from the ER to consistently raise intracellular $\mathrm{Ca}^{2+}$ levels. Our data with $\mathrm{Tn}$ (Figure 1) showed that injection with Tn results in increase in the cytosolic $\mathrm{Ca}^{2+}$ in photoreceptors. Previously, this treatment has been found to induce photoreceptor cell death in the mouse retina. ${ }^{4}$ Therefore, in the current study we performed a single subretinal injection with mix of A23187 and thapsigargin $(\mathrm{Tg})$, targeting the SERCA2b activity to create a new experimental rat model of retinal degeneration. A23187, a divalent cation ionophore, is widely used in laboratories to increase intracellular $\mathrm{Ca}^{2+}$ in intact cells. The dose of A23187 $(0.05 \mu \mathrm{g} / \mathrm{eye})$ was chosen based on a previously published in vitro study. ${ }^{28} \mathrm{Tg}$ is a non-competitive inhibitor of the SERCACa ${ }^{2+}$ ATPase. Therefore, injecting the $S D$ rat retinas with these drugs would be expected to result in increased cytosolic $\mathrm{Ca}^{2+}$. Retinas were analyzed 2, 4, and 6 weeks after injection by ERG and protein analyses to validate the effect of increased cytosolic $\mathrm{Ca}^{2+}$ on photoreceptor function and cellular signaling. Other retinal cell types in this model would also be expected to have increased cytosolic $\mathrm{Ca}^{2+}$. However, by registering the photoreceptororiginated scotopic a-wave ERG amplitudes vs b-wave amplitude originating mostly from bipolar cells, we measured functional changes occurring directly or indirectly in these cells, and tested the direct effects of increased $\mathrm{Ca}^{2+}$ specifically in rod photoreceptor cells. Experimental data from $\mathrm{Tg}$ - and A23187-injected retinas are presented in Figure $5 \mathrm{a}$ and Supplementary Table S7. These data demonstrated that injections led to a sustained decline in the scotopic ERG a- wave amplitudes at 2 and 6 weeks after drug administration (50\% and $49 \%$, respectively). This suggested that sustained increase in intracellular $\mathrm{Ca}^{2+}$ results in retinal functional loss. B-wave amplitude also declined in this model by $39 \%$ and $47 \%$ at 2 and 6 weeks, correspondingly.

To verify whether the decline in photoreceptor function was associated with photoreceptor cell loss, we further performed a histological analysis in which we stained retinal cryosections with H\&E (Figures $5 b$ and $c$ ). We found that the number of photoreceptor nuclei in drug-treated retinas was 36\% lower than in vehicle-treated retinas $(P<0.05)$, suggesting that injections resulted in $\mathrm{Ca}^{2+}$-induced retinal degeneration in the experimental rat model.

To characterize the experimental rat model of retinal degeneration, we harvested injected $(\mathrm{A} 23187+\mathrm{Tg})$ retinas $36 \mathrm{~h}$ post injection and analyzed the cellular signaling involved in photoreceptor cell loss. (Figures $5 \mathrm{~d}-\mathrm{g}$ and Supplementary Table S7). We found that injections resulted in a $43 \%$ 

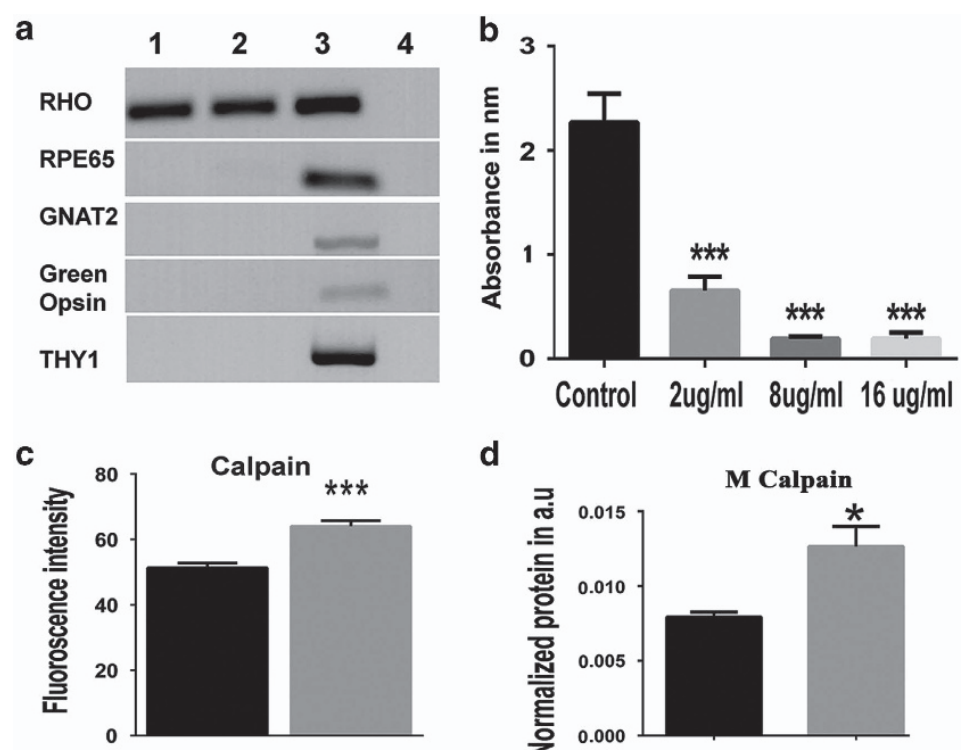

d
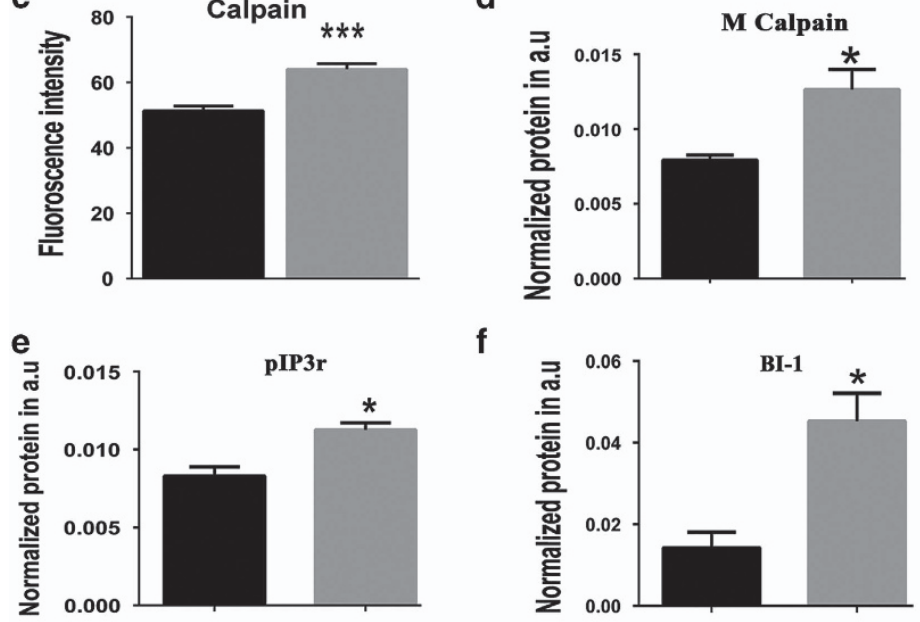

f
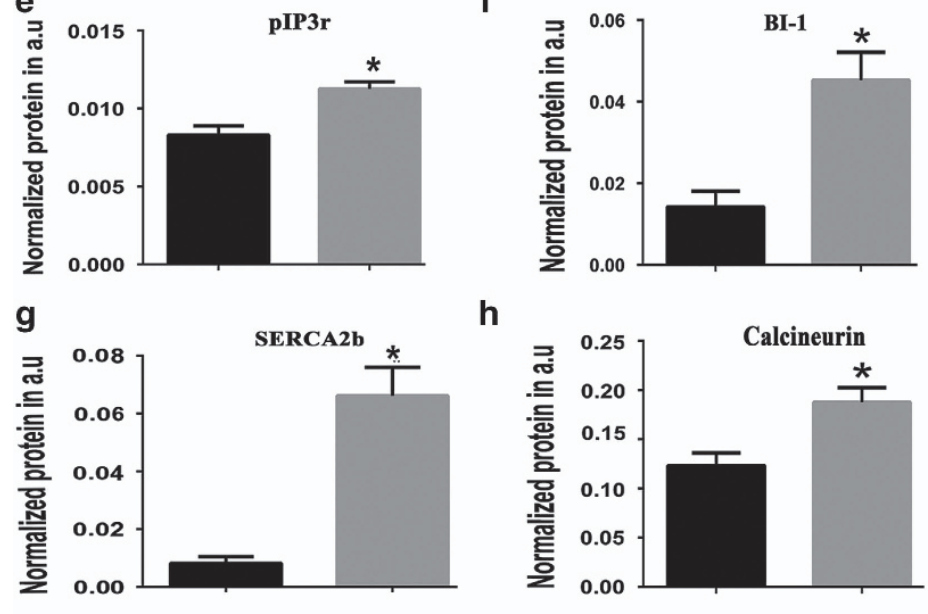

h

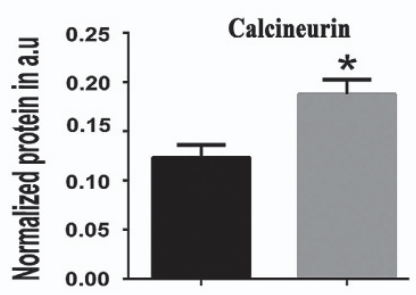

i

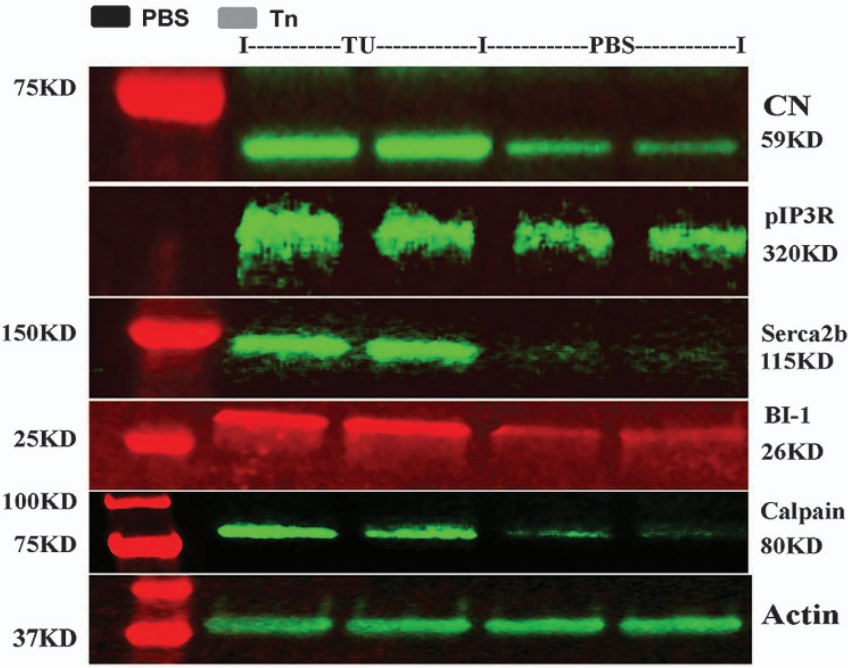


upregulation of calpain activity and 2.85 -fold increase in calcineurin expression at $36 \mathrm{~h}$ post injection, confirming the increase in cytosolic $\mathrm{Ca}^{2+}$ in the rat retina. We analyzed downstream calpain-activated targets and tested the CDK5 expression, which is known to be governed by calpain's processing of a proteolytic cleavage of the CDK5's activator, p35. The CDK5 level was significantly higher in A23187+ Tg-injected retinas than vehicle-injected retinas, pointing out the potential phosphorylation of the MEKK1 and activation of the JNK apoptotic pathway. ${ }^{29}$ To validate this hypothesis, we tested the pJNK level and found it to be $77 \%$ higher in druginjected retinas. Altogether, these data indicate that the apoptotic pathway was elevated in treated retinas. Therefore, we then verified caspase-3/7 activity and found almost a ninefold elevation of the caspase-3/7 activity in retinal extract treated with drugs.

\section{Discussion}

The presence of a $\mathrm{Ca}^{2+}$ overload in the nerve fiber layer and the inner nuclear layer in $\mathrm{P} 23 \mathrm{H}$ Rho rat retinas (line 1) has been reported recently. ${ }^{30}$ However, indirect indications of increased intracellular $\mathrm{Ca}^{2+}$ in degenerating photoreceptors have been provided only by the therapeutic modulation of $\mathrm{Ca}^{2+}$ blockers or inhibitors in their retinas. ${ }^{21,22}$ Our study is the first molecular genetic evidence, demonstrating that in the retina of rat models of $\mathrm{ADRP}, \mathrm{Ca}^{2+}$ release from the ER contributes to the mechanism of retinal degeneration. We first demonstrated an increase in intracellular $\mathrm{Ca}^{2+}$ during the ADRP progression in photoreceptors and linked this increase to a persistently activated UPR-induced ER $\mathrm{Ca}^{2+}$ depletion. Thus, we found that the modified expression of ER membrane $\mathrm{Ca}^{2+}$ channels and resident buffering proteins is associated with increased cytoplasmic $\mathrm{Ca}^{2+}$ and an elevation of mitochondrial VDAC. These events are in agreement with a previously reported cytochrome $C$ and AIF1 release from the mitochondria in these rats. ${ }^{1,2,31}$ In addition, we demonstrated that the ER perturbance in the retina is associated with $\mathrm{Ca}^{2+}$-induced calpain activation capable of triggering retinal degeneration in an experimental rat model.

Both ADRP rat models demonstrate the activation of the UPR at P21 and P30., ${ }^{2,30}$ Interestingly, although the rate of retinal degeneration in these two ADRP models differs, the level of the cytosolic $\mathrm{Ca}^{2+}$ increase in the P30 photoreceptors is similar. This suggests that the source of elevated intracellular $\mathrm{Ca}^{2+}$ in photoreceptors could be a result of malfunctioning ER and resulted extensive $\mathrm{Ca}^{2+}$ outflow from ER lumen. It is worth mentioning here that if for the pIP3R and
$\mathrm{Bl}-1$ both the mRNA and the protein level were upregulated, the CRN protein was not altered as compared with elevated Crn mRNA. Perhaps, discrepancy in a gene and protein expression in both groups can be easily explained by the recently reported correlation between the CRN overproduction and the $\mathrm{Ca}^{2+}$ overload within the ER. Thus, Michalak et al. ${ }^{32}$ has found that $50 \%$ of all $\mathrm{Ca}^{2+}$ stored in the ER binds to $\mathrm{CRN}$, and therefore, $\mathrm{CRN}$ protein overproduction indicates an elevation in the ER luminal Ca2+. Moreover, Waser et al. ${ }^{25}$ have demonstrated that overexpression of Crn mRNA is a sign of $\mathrm{ER} \mathrm{Ca}^{2+}$ depletion. Therefore, the upregulation of Crn mRNA expression and unaltered protein production indicate $\mathrm{ER} \mathrm{Ca}^{2+}$ reduction in both ADRP retinas.

Concomitantly with activated UPR and upregulated calpain activity have been previously shown, ${ }^{1,2,31}$ we observed the upregulation of calpastatin and calcineurin levels. In general, $\mathrm{CN}$ is known to regulate the activity of AKT through dephosphorylation. ${ }^{23}$ Therefore, we were not surprised to observe a marked increase in the $\mathrm{CN}$ protein in $\mathrm{P} 30 \mathrm{P} 23 \mathrm{H}$ Rho retinas that was in agreement with previously detected decrease of pAKT and upregulation of mTOR. ${ }^{1}$ All these data highlight a cellular defense mechanism activated in photoreceptors from $\mathrm{P} 21$ to $\mathrm{P} 40$ that is trying to cope with a launched mechanism of photoreceptor degeneration. However, the strength of such signaling seems to be insufficient to block $\mathrm{Ca}^{2+}$-induced calpain activation and, consequently, intracellular $\mathrm{Ca}^{2+}$ affects the mitochondrial homeostasis in these animals. As proof of this hypothesis, the observed VDAC elevation indicates a disrupted molecule flux across the outer mitochondrial membrane and suggests cross-talk between these two organelles.

Next, we were interested in testing whether sustained UPR activation is capable of triggering photoreceptor cell death via $\mathrm{Ca}^{2+}$-induced signaling. We have previously tested $\mathrm{Tn}$ in vivo and have demonstrated that the activation of the UPR induces retinal degeneration in mouse retinas. ${ }^{4}$ In this study, we demonstrated sustained UPR-induced cytotoxicity in a primary photoreceptor culture and in vivo and analyzed a signaling responsible for cell loss. Both in vitro and in vivo, Tn induces a calpain activation that is associated with disrupted ER $\mathrm{Ca}^{2+}$-sensing receptor expression. This implies that UPR-induced photoreceptor cell death occurs via $\mathrm{Ca}^{2+}$ outflow from ER lumen and $\mathrm{Ca}^{2+}$-mediated calpain signaling. However, to obtain direct evidence that the intracellular $\mathrm{Ca}^{2+}$ increase induced by persistently activated UPR in photoreceptors as seen in Figure 1 promotes retinal degeneration, we created an experimental rat model of $\mathrm{Ca}^{2+}$-induced retinal degeneration.

Figure 4 The tunicamycin treatment of primary photoreceptor cultures and the subretinal injection of tunicamycin in SD rats result in cell death by the activation of calpaininduced $\mathrm{Ca}^{2+}$ signaling. (a-c) Primary photoreceptor cultured cells were confirmed to express rod photoreceptor markers such as rhodopsin (lines 1 and 2 ) and to lack cone and ganglia cell markers such as GNAT2 and Thy-1 compared with whole retinal cell lysate (line 3) and negative controls (line 4). (a, b) Different concentrations of Tn were used to verify a dose of Tn at which a rod cell viability would be compromised measured by MTT assay $(N=6)$. The read absorbance correlated with viable cells. (c) The dose of $2 \mu \mathrm{g} / \mathrm{ml}$ Tn was used to test whether calpain activation occurred in Tn-treated rod photoreceptor cells $(N=3)$. Increase in calpain activity was found $18 \mathrm{~h}$ after treatment with Tn $(P<0.01)$. (d-i) $(N=4)$. The dose of $0.02 \mu \mathrm{g} /$ eye of Tn was used to inject SD retinas and then rat retinas were analyzed 4 days after injection $(P<0.05$ for all analyzed proteins compared to PBS injection). (d) The Tn injection resulted in the elevation of the calpain level. (e) In addition, an increase in the IP3R protein level was associated with Tn injection vs PBS-injected retinas. (f) This increase was in agreement with the elevated BI-1 protein and was opposite to the result of concomitant elevation of SERCA2b compared to PBStreated retinas. $(\mathbf{g}, \mathbf{h})$ Interestingly, the calcineurin protein level was also significantly increased in Tn-injected retinas. (i) Images of western blots treated with correspondent antibodies are shown. Data are shown as means \pm S.E.M. Images of western blots treated with a correspondent antibody are shown above the graphs for the calculation of individual proteins. ${ }^{*},{ }^{* *} P<0.01$ 
a

-. Vehicle - A23178+Tg
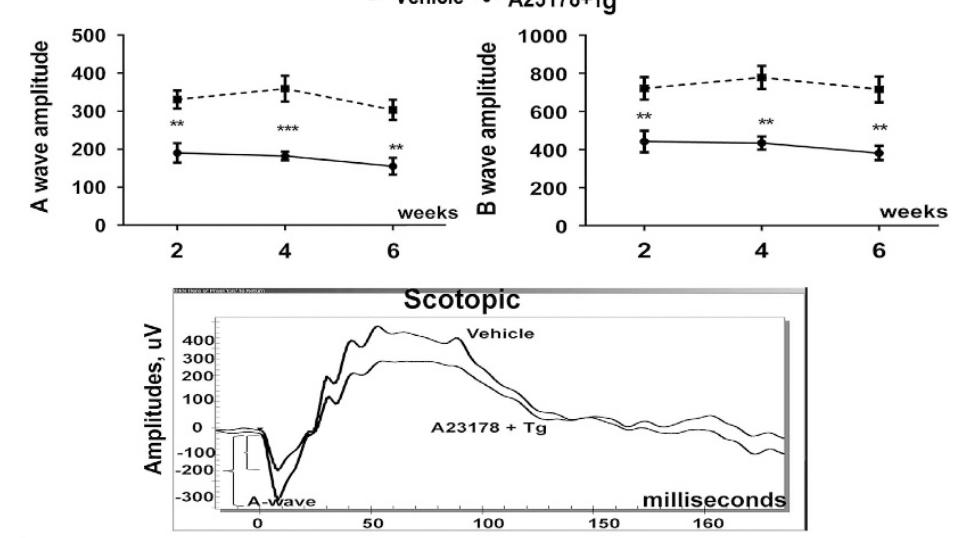

b
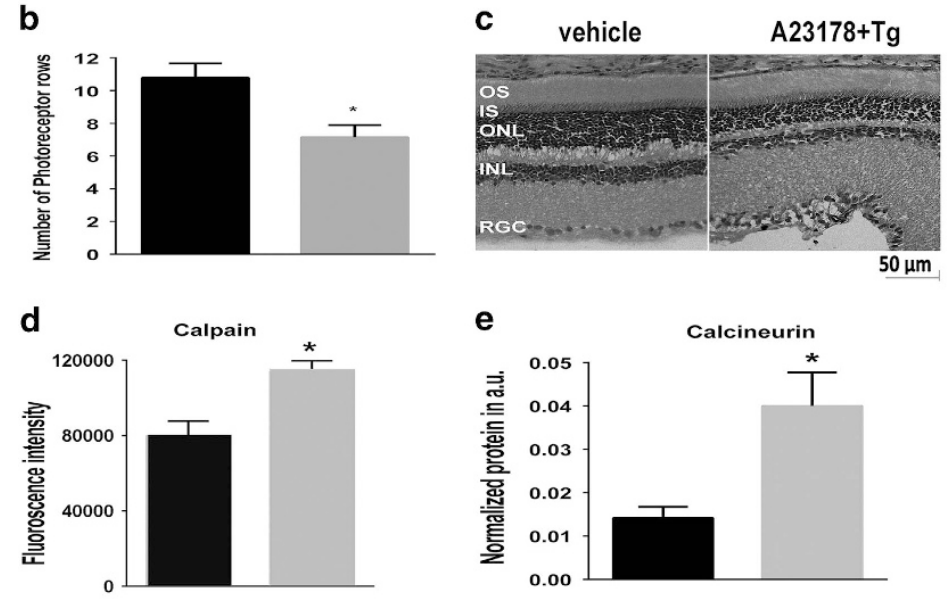

e

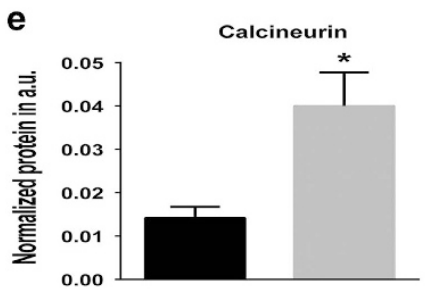

f

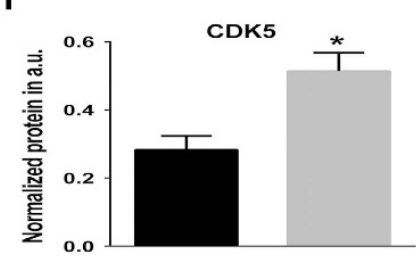

$9 \quad$ pJNK

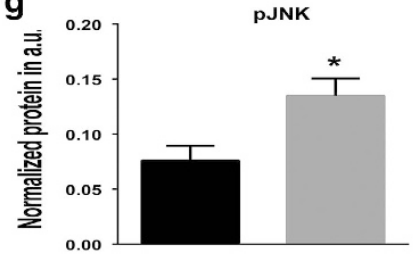

h

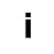

I--Treatment--I-----Vehicle-----I

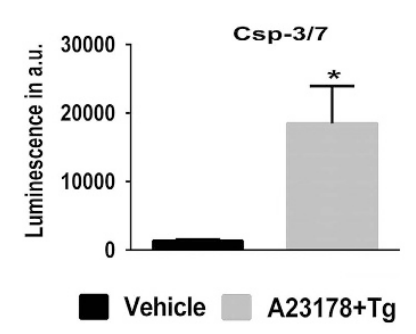

i

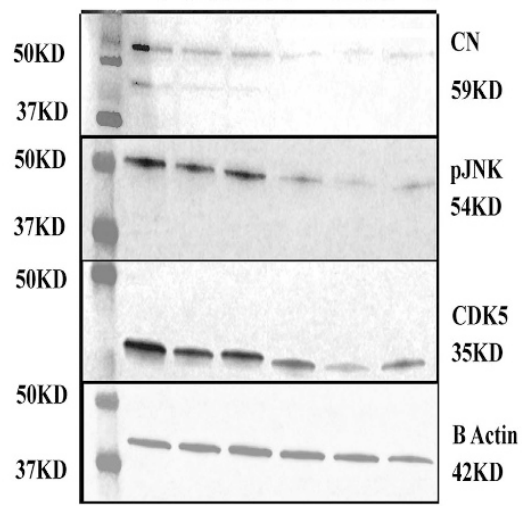

Figure 5 Subretinal injection of the combined A23178 and Tg drugs promotes retinal degeneration via $\mathrm{Ca}^{2+}$-mediated calpain activation. (a) Scotopic ERG analysis was shown at $10 \mathrm{~dB}\left(25 \mathrm{~cd}{ }^{*} \mathrm{~s} / \mathrm{m}^{2}\right)$. Analyzing by two-way ANOVA, reduction of the a-wave amplitudes was observed at 2,4 , and 6 weeks post injection, compared with vehicle-treated retinas $(P<0.01, P<0.001$, and $P<0.01$, respectively) $(N=4)$. The b-wave was also diminished compared with control-injected retinas $(P<0.01$ for all time points) $(N=4)$. Bottom: images of the scotopic ERG amplitudes registered at 10dB in two groups of animals are shown. (b) Subretinal injection of the combined A23187+Tg results in photoreceptor cell loss $(N=4)$. (c) Images of H\&E-stained retinal cryosections injected with drugs and vehicle. (d-h) Protein expression and activity assay performed $36 \mathrm{~h}$ posttreatment (for all $P<0.05$ ) $(N=4)$. (i) Images of western blots treated with correspondent antibodies are shown. B-actin served as a loading control. Data are shown as mean \pm S.E.M. ${ }^{* * * * * * \star} P<0.01$ 
Subretinal injection of the combined A23187 and Tg drugs triggers $\mathrm{Ca}^{2+}$-induced photoreceptor cell death. The rodderived a-wave amplitude of the scotopic ERG was significantly downregulated. In this model, the functional loss of photoreceptors is in agreement with a number of dying cells. Therefore, the findings from these experiments permit us to conclude that we created an experimental model of $\mathrm{Ca}^{2+}$-induced retinal degeneration. The experimental model mimics the inherited retinal degeneration occurring in rats, not only by the reduction of the scotopic ERG amplitudes and photoreceptor cell death, but also by the mechanism responsible for apoptotic photoreceptor cell death found in ADRP rat retinas. Perhaps, the $\mathrm{Ca}^{2+}$-calpain-CDK5-JNKcaspase- $3 / 7$ signaling activated by the injection of drugs is not the only mechanism by which the execution of photoreceptor cell death occurs. However, the fact of activated calpain suggests that this signaling also triggers apoptotic cell death. It also implies that a future experiment with photoreceptor-specific knockout or the overexpression of calpain is necessary to understand the role of calpain activation in retinal degeneration. Despite existing limitations, such as the cell specificity of responses to drug injection in the retina, the importance of experimental model for the field of retinal cell biology can be appreciated by applying genetically modified animals with the modified expression of $\mathrm{Ca}^{2+}$-sensing genes involved in neurodegeneration.

Therefore, our study revealed the involvement of $\mathrm{Ca}^{2+}$-activated cellular signaling in ADRP progression and indicated that manipulation with ER channels SERCA2b, IP3R, calpain, calpastatin and CDK5 expression during a UPR-induced cytosolic $\mathrm{Ca}^{2+}$ increase might be beneficial for patients with retinal degeneration.

\section{Materials and Methods}

Ethics statement. The animal protocol was carried out with approval from the Institutional Animal Care and Use Committee at the University of Alabama at Birmingham and in accordance with the guidelines of the Association for Research in Vision and Ophthalmology statement for the use of Animals in Ophthalmic and Vision Research. All efforts were made to minimize the number and the suffering of the animals used.

Animal models: Homozygous S334ter Rho (line 4) and P23H Rho (line 3) transgenic rats were maintained in the UAB housing facility and were bred with wildtype (WT) Sprague-Dawley (SD) rats to generate heterozygous S334ter-4 Rho and P23H-3 Rho rats. Therefore, the SD rats were used as WT controls in our experiments. The animals were killed on postnatal days (P) P13, P21, P30, P40, and $\mathrm{P} 60$ for RNA, protein analyses, calcium measurement, and photoreceptor isolation. All rats were maintained in specific pathogen-free conditions with a 12-h light-dark daily cycle.

Measurement of cytosolic calcium concentrations in photoreceptors: Retinas were harvested from S334ter, P23H, and SD rats under a dissecting microscope in dim red light. The retinas were incubated with $\mathrm{Ca}^{2+}$ indicator dye Fluo4 AM (Life Technologies, Grand Island, NY, USA; F14201-10 $\mu$ M) and Calceine red-orange AM to detect viable cells (Life Technologies C34851- $5 \mu \mathrm{M}$ ) for $90 \mathrm{~min}$ in Ames media at $36{ }^{\circ} \mathrm{C}$ (Sigma, St. Louis, MO, USA; pH 7.4, equilibrated with $95 \mathrm{O}_{2}$ and $5 \% \mathrm{CO}_{2}$ ) and Pluronic acid (Life Technologies P6866-10 $\mu \mathrm{M}$ ). Retinas were flat mounted to orient the photoreceptor cell side upwards in the perfusion chamber (perfused $2-4 \mathrm{ml} / \mathrm{min}$ with oxygenated Ames media at $36^{\circ} \mathrm{C}$ ). Flat-mounted retinas were imaged using infrared light on a Zeiss Axioskop microscope equipped with a $40 \times$ long working distance water-immersion objective. Fluo4 fluorescence was measured using a 488-nm excitation light from an Excite light source to detect fluorescence from free calcium. Viable cells were identified by Calceine fluorescence in response to a 577-nm excitation light, fluorescence images were acquired with an Axiocam hRM camera and Axiovision 4.6 software. Fluorescence levels of individual photoreceptors from all rat strains were measured and quantified from the fluorescence images of flat mount retinas using Image J. Only individual viable photoreceptors with both Calcein AM and Fluo4 AM fluorescence were counted.

RNA preparation and real-time PCR analysis: Retinas from SD, S334ter-4 Rho, and P23H-3 Rho rats were isolated at P13, P21, P30, P40, and P60. Total RNA was isolated from the individual retinas from each strain using Trizol $(N=5)$. CDNA was prepared using a cDNA Reverse transcription kit (Applied Biosystems, Foster City, CA, USA) from the RNA extracts of SD, S334ter-4 Rho, and P23H-3 Rho retinas. Each cDNA (20 ng) was subjected to qRT-PCR using Applied Biosystems TaqMan assays (validated for each selected gene) on a One Step Plus instrument (Applied Biosystems) to compare the number of cycles (Ct) needed to reach the midpoint of the linear phase. All observations were normalized to the GAPDH-housekeeping gene. The replicated RQs (Relative Quantity) values for each biological sample were averaged. Biological samples from each strain were used for the qPCR data analysis.

Retinal protein extract for western blot analysis: Retinal protein extracts were obtained from dissected retinas by sonication in a buffer containing $25 \mathrm{mM}$ of sucrose, $100 \mathrm{mM}$ of Tris- $\mathrm{HCl}, \mathrm{pH}=7.8$, and a mixture of protease inhibitors (PMSF, TLCK, aprotinin, leupeptin, and pepstatin). The total protein concentration in the right and left retinas from individual rat pups was measured using a Biorad protein assay, and $40 \mu \mathrm{g}$ of total protein was used to detect individual proteins. The detection of proteins was performed using an infrared secondary antibody and an Odyssey infrared imager (Li-Cor, Inc., Lincoln, NE, USA). Antibodies against phosphorylated (p) IP3R (\#S1756), Calpastatin (\#4146S), M-Calpain (\#2556S), and P-SAPK/JNK (46668P) are from Cell Signaling Technology. Serca2b (\#ab2861), Calcineurin (ab3673), antibodies were purchased from Abcam (Cambridge, MA, USA). BI-1 was obtained from Novus Biologicals (Littleton, CO, USA; \#NBP224912), antibodies against Bip (\#SC-1050) and CDK5 (SC173) from Santa Cruz (Dallas, TX, USA); and B-actin from Sigma-Aldrich (St. Louis, MO, USA; \#A1978). All antibodies we used at a dilution of $1: 1000$.

\section{Intravitral injection}

Two different treatment groups were generated by intravitreal drug injections. In the 1st group, SD rats at P21 were injected intravitreally with UPR inducer Tn ( $2 \mu \mathrm{g}$ Sigma T7765) and contralateral eyes were injected with vehicle. Retinas were extracted at post injection days 1,4 , and 8 from injected eyes and compared for the protein expression of the markers of calcium-induced apoptosis with western blot. In the next treatment, different groups of SD rats at P21 were injected intravitreally with calcium ionophore A23187 (500 ng Sigma \#C7522) and thapsigargin (100 ng Sigma \#T9033) together. Injected animals were analyzed for retinal functional testing (ERG) 2, 4, and 6 weeks following the injection as well as for the activation of calcium-induced apoptosis $36 \mathrm{~h}$ after injection.

Scotopic ERG: Rats were dark-adapted overnight, then anesthetized with ketamine $(100 \mathrm{mg} / \mathrm{kg})$ and xylazine $(10 \mathrm{mg} / \mathrm{kg})$. The pupils were dilated in dim red light with $2.5 \%$ phenylephrine hydrochloride ophthalmic solution (Akorn, Inc., Lake Forest, IL, USA). Scotopic ERGs were recorded using a wire contacting the corneal surface with $2.5 \%$ hypromellose ophthalmic demulcent solution (Akorn). The ERG was performed at the following light intensities: $-20 \mathrm{~dB}\left(0.025 \mathrm{~cd}^{*} \mathrm{~s} / \mathrm{m}^{2}\right),-10 \mathrm{~dB}$ $\left(0.25 \mathrm{~cd}^{*} \mathrm{~s} / \mathrm{m}^{2}\right), 0 \mathrm{~dB}\left(2.5 \mathrm{~cd}^{*} \mathrm{~s} / \mathrm{m}^{2}\right), 5 \mathrm{~dB}\left(7.91 \mathrm{~cd}^{*} \mathrm{~s} / \mathrm{m}^{2}\right), 10 \mathrm{~dB}\left(25 \mathrm{~cd}^{*} \mathrm{~s} / \mathrm{m}^{2}\right)$, and $15 \mathrm{~dB}$ $\left(79.1 \mathrm{~cd}^{*} \mathrm{~s} / \mathrm{m}^{2}\right)$. Five scans were performed and averaged for each light intensity. The a-wave amplitudes were measured from the baseline to the peak in the cornea-negative direction, and the b-wave amplitudes were determined from the cornea-negative peak to the major cornea-positive peak. The signal was amplified, digitized, and stored using the LKC UTAS-3000 Diagnostic System (Gaithersburg, MD, USA).

Calpain activity assay. The detection of calpain activity was performed using the Calpain Activity Assay kit from BioVision according to the manufacturer's recommendations. The activation of calpains in intravitreal drug-injected (calcium ionophore and $\mathrm{Tg}$ ) and vehicle-injected SD retinal tissues was compared. The detection of the cleavage substrate AC-LLY-AFC was performed in a fluorometer that 
was equipped with a 400-nm excitation filter and 505-emission filter (Perkin Elmer, Waltham, MA, USA; 1420 multilabel counter Victor ${ }^{3} \mathrm{~V}$ ).

Caspase-3/7 activity assay. Caspase-3/7 activity was measured using Caspase-3/7-Glo assay system kit from Promega (Madison, WI, USA; \#G8090) as per the manufacturer's instructions. The retinal protein extract of intravitreal drug(calcium ionophore and $\mathrm{Tg}$ ) and vehicle-treated SD animals were compared for caspase-3/7 activity. The luminescent signal generated from caspase cleavage by substrate was measured in a luminometer (Perkin Elmer 1420 multilabel counter Victor $\left.^{3} \mathrm{~V}\right)$.

Histological analysis: Rats were killed using a $\mathrm{CO}_{2}$ chamber. The eyeballs were enucleated, affixed in 4\% freshly made paraformaldehyde (Cat\# S898-09 J.T. Baker, Phillipsburg, NJ, USA), and kept at $4^{\circ} \mathrm{C}$ for $8 \mathrm{~h}$. Then, the eyes were hemisected and the eyecups were transferred to fresh PBS to remove formaldehyde and then immersed in a 30\% sucrose solution for cryoprotection. Eyecups were then embedded in a cryostat compound (Tissue TEK OCT, Sakura Finetek USA, Inc., Torrance, CA, USA) and frozen at $-80^{\circ} \mathrm{C}$. Twelve-micron sections were obtained using a cryostat. To count the nuclei of photoreceptors, we stained cryostat-sectioned retinas with H\&E using an H\&E stain Kit (Cat\#3490). Other slides were used for immunohistochemistry. Digital images of the right and left retinas of individual rats were taken, and the outer segment length was analyzed in the central superior and inferior retinas, located equidistant from the $\mathrm{ONH}$. Images were analyzed by an investigator blinded to the experimental conditions. All sections were examined on a microscope equipped with a digital camera (Carl Zeiss Axioplan2 Imaging microscope B000707, Carl Zeiss, Gottingen, Germany).

Immunohistochemical analysis: Twelve-micron sections were obtained and fixed on polylysine-treated glass slides. Slides were warmed for $30 \mathrm{~min}$ at $37^{\circ} \mathrm{C}$ and washed in $0.1 \mathrm{M}$ PBS for $10 \mathrm{~min}$ three times. Slides were kept in blocking buffer with $10 \%$ normal goat serum and $0.3 \%$ Triton solution for $1 \mathrm{~h}$ at room temperature and washed with PBS three times. The sections were incubated with primary antibody for VDAC (Cell Signaling, Danvers, MA, USA; \#4866 S) at $4{ }^{\circ} \mathrm{C}$ overnight. The slides were then washed three times with PBS and incubated with secondary antibody for $1 \mathrm{~h}$ at room temperature. After washing, the sides were cover slipped using a mounting medium containing DAPI and allowed to dry for $1 \mathrm{~h}$. Images were using a wide-field fluorescence microscope (Carl Zeiss Axioplan2 Imaging microscope B000707, Carl Zeiss).

Photoreceptor isolation: Petri dishes were incubated for $2 \mathrm{~h}$ at $37^{\circ} \mathrm{C}$ with $2.5 \mu \mathrm{g} / \mathrm{cm}^{2}$ anti WGA directed against wheat-germ agglutinin (WGA) lectin (vector laboratories, Burlingame, CA, USA). Anti-WGA was diluted in $25 \mathrm{mM}$ of bicarbonate buffer ( $\mathrm{pH} 8$ ), with $0.9 \% \mathrm{NaCl}$ and $2 \mathrm{mg} / \mathrm{ml}$ of BSA. After three washes with warm bicarbonate buffer, the dishes were consequently coated with $5 \mu \mathrm{g} / \mathrm{cm}^{2}$ of WGA lectin (vector laboratories) diluted in bicarbonate buffer and incubated for $2 \mathrm{~h}$ at $37^{\circ} \mathrm{C}$. After incubation, the petri dishes were washed with warm PBS and stored in $0.2 \%$ BSA in PBS until used.

The retinas from 30-day-old SD rats were harvested under dim red light, and the retinas were suspended in cold Hybernate A media (Life Technologies). Each retina was transferred to a tube with $1 \mathrm{ml}$ of HybA and warmed for $8 \mathrm{~min}$ at $37^{\circ} \mathrm{C}$ in a water bath. The warmed HybA media was aspirated, and the retina was incubated with Papain $(0.06 \mathrm{mg} / \mathrm{ml}$ Worthington biochemical, Lakewood, NJ, USA) in HybA for $20 \mathrm{~min}$ at $37^{\circ} \mathrm{C}$ in a water bath with gentle shaking every $10 \mathrm{~min}$. Papain solution was aspirated and $1 \mathrm{ml}$ of $2 \%$ FBS solution in HybA was added to the retina and incubated for $5 \mathrm{~min}$ at room temperature to stop the enzymatic reaction. FBS solution was aspirated and Neurobasal (NBA) media supplemented with $1: 50$ B27 and $0.5 \mathrm{mM}$ of L-Glutamine was added to the tissue. For the dissociation of the retinal cells, the treated retinas were manually pipetted (gently 5-6 times) using $1000 \mu \mathrm{l}$ and $200 \mu \mathrm{l}$ tips. The retinal suspension containing dissociated cells was collected.

The retinal suspension was placed on lectin-coated petri dishes and incubated for $30 \mathrm{~min}$ at $37^{\circ} \mathrm{C}$ with gentle swirling every $10 \mathrm{~min}$. After incubation, non-adherent cells were removed by washing them with serum-free NBA media. The attached cells were dissociated with pipetting and seeded with $4 \times 10^{5} \mathrm{~cm}^{2}$ in NBA media supplemented with B27 and Glutamine.

Semi-quantitative RT-PCR: Semi-quantitative RT-PCR was performed with CDNAs prepared from photoreceptors isolated from the WT rats. PCR products were detected using 1\% agarose gel and UV light based imager (Life Technologies).
Primer sequences (Sigma-Aldrich) for different retinal cell specific markers are provided in Supplementary Table S1.

MTT assay. Cell viability was assessed by a 3-(4, 5-dimethylthiazol- 2-yl)-2-5diphenyl tetrazolium bromide (MTT) assay. Then, $1 \times 10^{5}$ cells/well were seeded into 96-well micro-culture plates at $37^{\circ} \mathrm{C}$ with $5 \% \mathrm{CO} 2$ and allowed to attach for $24 \mathrm{~h}$. Cells were treated with designated doses of Tn for $48 \mathrm{~h}$ and incubated with MTT at a final concentration of $0.5 \mathrm{mg} / \mathrm{ml}$ for $4 \mathrm{~h}$ before the completion of the exposure time at $37^{\circ} \mathrm{C}$. The formation of MTT to formazon crystals by viable cells was assessed using $200 \mu /$ well of DMSO at room temperature for $15 \mathrm{~min}$. Optical density was measured at $490 \mathrm{~nm}$ using a micro-plate reader model 680 (Bio-Rad, Hercules, CA, USA). The reduction in viability of cells in each well was expressed as the percentage of control cells.

Statistical analysis. Two-way ANOVA comparisons were used to calculate the statistical significance of differences in fold-change of mRNA expression and levels of pIP3R protein in rats. A one-way ANOVA test was used to calculate the statistical significance of differences in levels of normalized proteins in P21 ADRP retinas and $\mathrm{Ca}^{2+}$ detection in ADRP photoreceptors. For comparisons of protein levels and $\mathrm{Ca}^{2+}$ detection in Tn-injected and controlled retinas we used the Student's t-test. To calculate the statistical significance of differences in the a- and b-wave ERG amplitudes, a two-way ANOVA was applied. For all experiments, a $P$-value lower than 0.05 was considered to be significant $\left({ }^{*} P<0.05\right.$, ${ }^{* *} P<0.01$, ${ }^{* *} P<0.001$, $\left.{ }^{\star * \star *} P<0.0001\right)$

\section{Conflict of Interest}

The authors declare no conflict of interest.

Acknowledgements. This work was supported by the National Institutes of Health Grant R01EY020905 and the VSRC Core Grant P30 EY003039.

1. Sizova OS, Shinde VM, Lenox AR, Gorbatyuk MS. Modulation of cellular signaling pathways in P23H rhodopsin photoreceptors. Cell Signal 2014; 26: 665-672.

2. Shinde VM, Sizova OS, Lin JH, LaVail MM, Gorbatyuk MS. ER stress in retinal degeneration in S334ter Rho rats. PLoS One 2012; 7: e33266.

3. Kaur J, Mencl S, Sahaboglu A, Farinelli P, van Veen T, Zrenner E et al. Calpain and PARP activation during photoreceptor cell death in $\mathrm{P} 23 \mathrm{H}$ and S334ter rhodopsin mutant rats. PLOS One 2011; 6: e22181.

4. Rana T, Shinde VM, Starr CR, Kruglov AA, Boitet ER, Kotla P et al. An activated unfolded protein response promotes retinal degeneration and triggers an inflammatory response in the mouse retina. Cell Death Dis 2014; 5: e1578.

5. Mekahli D, Bultynck G, Parys JB, De Smedt H, Missiaen L. Endoplasmic-reticulum calcium depletion and disease. Cold Spring Harbo Perspect Biol 2011; 3 PubMed PMID: 21441595. Pubmed Central PMCID: 3098671.

6. Bravo R, Parra V, Gatica D, Rodriguez AE, Torrealba N, Paredes F et al. Endoplasmic reticulum and the unfolded protein response: dynamics and metabolic integration. Int Rev Cell Mol Biol 2013; 301: 215-290.

7. Kaufman RJ, Malhotra JD. Calcium trafficking integrates endoplasmic reticulum function with mitochondrial bioenergetics. Biochim Biophys Acta 2014; 1843: 2233-2239.

8. Mallilankaraman K, Cardenas C, Doonan PJ, Chandramoorthy HC, Irrinki KM, Golenar T et al. MCUR1 is an essential component of mitochondrial $\mathrm{Ca} 2+$ uptake that regulates cellular metabolism. Nat Cell Biol 2012; 14: 1336-1343.

9. Mallilankaraman K, Doonan P, Cardenas C, Chandramoorthy HC, Muller M, Miller R et al. MICU1 is an essential gatekeeper for MCU-mediated mitochondrial $\mathrm{Ca}(2+)$ uptake that regulates cell survival. Cell 2012; 151: 630-644.

10. Sancak Y, Markhard AL, Kitami T, Kovacs-Bogdan E, Kamer KJ, Udeshi ND et al. EMRE is an essential component of the mitochondrial calcium uniporter complex. Science 2013; 342: 1379-1382.

11. Krizaj D. Calcium stores in vertebrate photoreceptors. Adv Exp Med Biol 2012; 740: 873-889.

12. Molnar T, Barabas P, Birnbaumer L, Punzo C, Kefalov V, Krizaj D. Store-operated channels regulate intracellular calcium in mammalian rods. J Physiol 2012; 590: 3465-3481.

13. Hoppe UC. Mitochondrial calcium channels. FEBS Lett 2010; 584: 1975-1981.

14. Arango-Gonzalez B, Trifunovic D, Sahaboglu A, Kranz K, Michalakis S, Farinelli P et al. Identification of a common non-apoptotic cell death mechanism in hereditary retinal degeneration. PloS One 2014; 9: e112142.

15. Barabas P, Cutler Peck C, Krizaj D. Do calcium channel blockers rescue dying photoreceptors in the Pde6b (rd1) mouse? Adv Exp Med Biol 2010; 664: 491-499. 
16. Paquet-Durand F, Sanges D, McCall J, Silva J, van Veen T, Marigo V et al. Photoreceptor rescue and toxicity induced by different calpain inhibitors. J Neurochem 2010; 115: 930-940.

17. Sanges D, Comitato A, Tammaro R, Marigo V. Apoptosis in retinal degeneration involves cross-talk between apoptosis-inducing factor (AIF) and caspase- 12 and is blocked by calpain inhibitors. Proc Natl Acad Sci USA 2006; 103: 17366-17371.

18. Ozaki T, Nakazawa M, Yamashita T, Sorimachi H, Hata S, Tomita H et al. Intravitreal injection or topical eye-drop application of a mu-calpain C2L domain peptide protects against photoreceptor cell death in Royal College of Surgeons' rats, a model of retinitis pigmentosa. Biochim Biophys Acta 2012; 1822: 1783-1795.

19. Sorimachi H, Ono Y. Regulation and physiological roles of the calpain system in muscular disorders. Cardiovasc Res 2012; 96: 11-22.

20. Krizaj D, Copenhagen DR, Calcium regulation in photoreceptors. Front Biosci 2002; 7: d2023-d2044.

21. Ozaki T, Ishiguro S, Hirano S, Baba A, Yamashita T, Tomita H et al. Inhibitory peptide of mitochondrial mu-calpain protects against photoreceptor degeneration in rhodopsin transgenic S334ter and P23H rats. PLoS One 2013; 8: e71650.

22. Bush RA, Kononen L, Machida S, Sieving PA. The effect of calcium channel blocker diltiazem on photoreceptor degeneration in the rhodopsin Pro213His rat. Investig Ophthalmol Vis Sci 2000; 41: 2697-2701.

23. Evans RC, Herin GA, Hawes SL, Blackwell KT. Calcium-dependent inactivation of calcium channels in the medial striatum increases at eye opening. J Neurophysiol 2015; 113: 2979-2986.

24. Shoshan-Barmatz V, Ben-Hail D. VDAC, a multi-functional mitochondrial protein as a pharmacological target. Mitochondrion 2012; 12: 24-34.

25. Waser M, Mesaeli N, Spencer C, Michalak M. Regulation of calreticulin gene expression by calcium. J Cell Biol 1997; 138: 547-557.

26. Kiviluoto S, Schneider L, Luyten T, Vervliet T, Missiaen L, De Smedt H et al. Bax inhibitor-1 is a novel IP(3) receptor-interacting and -sensitizing protein. Cell Death Dis 2012; 3: e367.
27. Sano R, Reed JC. ER stress-induced cell death mechanisms. Biochim Biophys Acta 2013; 1833: 3460-3470.

28. Przygodzki T, Sokal A, Bryszewska M. Calcium ionophore A23187 action on cardiac myocytes is accompanied by enhanced production of reactive oxygen species. Biochim Biophys Acta 2005; 1740: 481-488.

29. Kang MJ, Chung J, Ryoo HD. CDK5 and MEKK1 mediate pro-apoptotic signalling following endoplasmic reticulum stress in an autosomal dominant retinitis pigmentosa model. Nat Cell Biol 2012; 14: 409-415.

30. Caminos $\mathrm{E}$, Vaquero $\mathrm{CF}$, Martinez-Galan JR. Relationship between rat retinal degeneration and potassium channel KCNQ5 expression. Exp Eye Res 2015; 131: 1-11.

31. Gorbatyuk MS, Knox T, LaVail MM, Gorbatyuk OS, Noorwez SM, Hauswirth WW et al Restoration of visual function in $\mathrm{P} 23 \mathrm{H}$ rhodopsin transgenic rats by gene delivery of $\mathrm{BiP} /$ Grp78. Proc Natl Acad Sci USA 2010; 107: 5961-5966.

32. Michalak M, Groenendyk J, Szabo E, Gold LI, Opas M. Calreticulin, a multi-process calcium-buffering chaperone of the endoplasmic reticulum. Biochem $\mathrm{J} 2009 ; 417$ : 651-666.

(c) Cell Death and Disease is an open-access journal published by Nature Publishing Group. This work is licensed under a Creative Commons Attribution 4.0 International License. The images or other third party material in this article are included in the article's Creative Commons license, unless indicated otherwise in the credit line; if the material is not included under the Creative Commons license, users will need to obtain permission from the license holder to reproduce the material. To view a copy of this license, visit http://creativecommons.org/licenses/by/4.0/ 